\title{
Основы мыслительной деятельности
}

\section{ВВОДНАЯ ЧАСТЬ}

Подспудные догадки относительно истинной эволюционной сути земных организмов, являющихся никакими не божественными созданиями, а простыми биороботами, преследовали человечество давно. И даже, к слову, тот весьма_щекотливый для нас расклад, при котором и «его величество» Homo sapeens тоже может олицетворять собой некую искусственную, а не реально существующую ипостась, обсуждался в свое время как солипсистами (Лао-цзы, Будда, Горгий, Брюне), так и другими известными мудрецами древности; но, правда, в несколько уже ином ракурсе.-

Однако в серьезной науке одних лишь спекулятивных досужих разглагольствований явно недостаточно - требовались конкретные аргументы. И вот ровно полтора века тому назад* в Петербурге вышла эпохальная, без преувеличения можно сказать, книга “Рефлексы головного мозга", где все эти доказательства были наглядно как раз и вполне убедительно представлены. И хоть против самого «отца российской физиологии» И.М.Сеченова тут же мигом ополчилось немало тогдашних религиозных деятелей, обвинив его в богохульстве, аморальности и прочих тяжких неискупимых грехах, - однако соответствующий зачин был, как говорится, успешно положен, да и к тому же надежно задокументирован. С чем, кстати, в итоге согласилось и большинство мирового ученого сообщества. А уже в середине следующего столетия эти прогрессивные идеи нашего прославленного земляка были творчески подхвачены американцем Норбертом Винером, фактически уравнявшим любое живое существо с машиной.

Но всё же, как бы там ни было, в предлагаемой тут вашему вниманию новом своём философском трактате автор делает смелую отчаянную попытку еще глубже проникнуть в потайные лабиринты челочеческой психики - мысленно насквозь сканируя внутриклеточное пространство и обосновывая сам по себе эволюционный механизм оптимального программного управления в донельзя_сложных и запутанных нервных сетях.

Да уж, действительно, спорить здесь особо не приходится: все мы - эстетически изящные, нравственно безупречные и очень притом эрудированные биороботы! Но только вот почему же, впрочем, многие на практике так настороженно, а подчас даже и воинственно к этому относятся? Да потому что в сфрере высшего 
медицинского (как, кстати, и гуманитарного) образования СНГ попрежнему всё еще безраздельно господствует кондовый марксистско-ленинский материализм. Подлинного же идеалистического крыла (подчеркну: не религиозного, а именно научно-исследовательского), по сути, просто-напросто нету. Ну, за исключением разве что каких-то считанных энтузиастов-одиночек (наподобие Н.П.Бехтеревой, В.И.Цымбалюка, В.Д.Мишиева, Ю.П.Зинченко, Ю.С.Шойгу). И хотя новое передовое знание неудержимым стремительным потоком начало всё ж таки сейчас уже выплескиваться наружу, однако для него заведомо маловато пока еще, на наш взгляд, надлежащей государственной поддержки.

Что ж, постараемся тогда уж хотя бы в этом своём теоретическом обзоре каким-то доступным образом исправить такую не весьма приятную тенденцию.

\section{I}

Человеческая память функционирует на нескольких уровнях. Первичная напрямую связана с сенсорным запечатлеванием и локализуется в таламусе. Это по сути дела монадная память. Эмоционально окрашенные информационные ощущения несколько секунд спустя можно ещё восстановить в сознании за счёт реверберации нервных импульсов по таламусу (а иногда и вышележащим мозговым слоям, отвечающим, например, за восприятие речи, жестов, иероглифов и других сложных символов).

К слову, лимбические структуры (включая сюда и гиппокамп) способны принимать не только целевые приказы из таламуса, но и улавливать эмоциональный фон любых адекватно закодированных сообщений, поступающих в приемлемом для них виде из коры. Гиппокамп ответственен, кроме того, и за функционирование у человека оперативной памяти.

Как уже было сказано об этом ранее, в ходе исторической эволюции природных систем довольно-таки отчётливо прослеживается преемственность в структуре и способе формирования ощущений и эмоций, характерных для данного конкретного этапа. Но всё же наиболее хорошо это видно на примере памяти, ведь краткосрочная память каждой последующей системы базируется на мнемо-субстрате предыдущей.

Кстати говоря, сиюминутно-реверберативная память также, по-видимому, присутствует на любой ступеньке эволюционной иерархии, но она прежде всего зависит от самого импринтинга и путей проведения сигналов, а не от низлежащих структур, поскольку разноуровневые системы по-разному воспринимают ход времени, а значит - и последовательную хронологию событий. 
Хотя специфическая фундаментальная память хордовых зиждется, в принципе, на астроцитах, но тем не менее, если понадобится, вполне способна апеллировать и к долгосрочной мнемо-субстанции низшего порядка, представленной, по идее, внутриядерными (но иногда, возможно, и внеклеточными) белками**. Однако у всех без исключения людей долговременная память (приуроченная - напомним - к серому веществу коры обоих полушарий) формируется из оперативной и причём, как правило, в минуты сенсорного затишья, т.е. в основном днём. Ночью же какими-то периодическими урывками (ибо большинство времени мозг попросту отдыхает) доделывается лишь то, что не успелось в течение светлой поры суток.

Хотя астроциты (обладающие, как известно, гораздо меньшим эволюционным «стажем») хранят свою базу данных в аналоговом виде, а пептиды - в цифровом, обе эти функции носят всё ж таки строго избирательный характер. Причём в ходе отбора более важного материала уже имеющиеся до этого в нейронах белкипонятия заведомо играют ведущую роль, а подкорковые структуры, ответственные за оперативную память, - лишь второстепенную. Феномен же тотального запоминания присущ лишь первичному «я» (да и то востребовать подобную информацию далеко не каждому по силам).

II

Человеческое мышление основано на долговременной памяти и формируется в ареалах, непосредственно прилегающих $\mathrm{k}$ соответствующим сенсорным анализаторам в коре головного мозга. Одни и те же понятия, что вполне естественно, способны при этом неоднократно дублироваться в зависимости от их этиологической природы. К тому же тут еще следует учитывать возможное разветвление логосов не только в сенсорном аспекте, но также и на более высоком порядковом уровне: в качестве омонимов, синонимов, идиом, неологизмов и даже по сугубо эмоциональным признакам. Причём новые астроцитные и белковые понятия выстраиваются (с

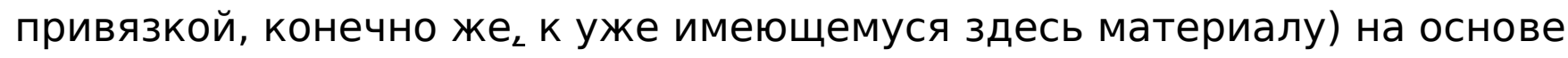
свежих релевантных образов, достойных быть занесенными в долговременную память.

В толще больших полушарий, так же примерно, как и в сложных кибернетических устройствах или предложениях формальной логики, существуют свои иерархические пирамиды, на вершине которых располагаются сверхпонятия. Кроме того, там же есть и структуры, отвечающие за функционирование принципа обратной связи, ассоциативные зоны, аналоги категориально-семантического аппарата и многое другое. Кстати, в формальной логике, можно сказать, вообще 
нет ничего такого, что не было бы так или иначе реализовано в мозгу высокоразвитых представителей земной фауны. Так, пользуясь известным законом: "Если из А следует B, то из не-В следует не-А", мы должны быть готовы к нахождению белка "не-В", непосредственно связанного с белком "не-А". Разумеется, такие абстрактные структуры с целью экономии пространства закладываются в основном на уровне сверхпонятий.

За связь между отдельными белками-понятиями отвечают конкретные «подведомственные» хромосомы, а вот за формирование результирующих ассоциативных треков - как раз уже сами нейроны, пользующиеся, по-видимому, для этого обычными электрическими импульсами (в отличие от кодированных звуковых сигналов своих нуклеиновых предтеч). Эти нейроны могут работать в любое время вне зависимости от направленности сознания, но в основном делают это днем, в период бодрствования. При замыкании длинных силлогистических цепочек "белок А - белок В - белок С - белок Д" посредством "белок А - белок Д" клетки возбуждаются, выражая радость, что, как известно, ведет к выделению дополнительной энергии. Энергия, преобразуясь в нервный импульс, достигает таламуса, хотя и отнюдь не всегда должным образом там воспринимается. Если сигнал для организма не актуален, "я" на него не реагирует. В других же случаях оно и само может послать запрос в кору, если надо что-то вспомнить или срочно найти ответ. Такой путь общения намного более действенный.

Что же касается астроцитов, то они здесь (и прежде всего - в складках серого вещества) выступают только в качестве пассивных (хотя и довольно надежных) хранителей памяти. Причем, как уже было сказано выше (см. предыдущий раздел), автор склонен считать, что она несёт в себе аналоговый, а не цифровой код, будучи напрямую обусловлена тесным биохимическим взаимодействием между глио- и нейро-трансмиттерами.

\section{III}

Итак, в отличие от мгновенного узнавания с чувственным подтекстом, все прочие реминисцентные образы (т.е. не связанные с острыми сиюминутными нуждами индивида) обязаны своим генезисом исключительно лишь коре. Передаются они, быть может, и квантово-волновым путем, но проецируются в человеческое сознание всё ж таки наверняка уж через вполне привычный для нас вещественный (а точнее - монадный) субстрат. Причем практически то же свмое следует сказать и о разного рода мечтах, фантазиях, сложных многоступенчатых абстракциях, ну и, конечно, о любых умственно-созидательных процессах, характерных, так или иначе, для серьёзной научной деятельности. И хотя их реализация, по 
сути, мало чем отличается от сходных ранее описанных нами явлений, протекающих в сенсорных ядрах, но тут уже, однако, требуется всё же непосредственное активное участие и высших (кортикальных) мозговых структур. Во-первых, создается абстрактный образ наблюдателя, с точки зрения которого рассматривается представляемый объект; во-вторых,_ дополнительно сюда еще привлекаются такие формальнологические категории, как величина, размерность, угол восприятия и т.п. Все эти операционные процедуры входят в обязанности мышления, а окончательно созданный образ передается в центральное "я". Хотя последнему вместе с тем тоже ни в коем разе не допустимо отводить в этих процессах какую-то мелкую сугубо факультативную роль. Вот, к примеру, одно из наиболее наглядных подтверждений сказанного: издавна хорошо известно, что у слабовольных людей не бывает, как правило, устойчивых и достаточно прочных мысленных ассоциаций. Возникающие у них образы зыбки, расплывчаты и быстро улетучиваются из сознания, то и дело сменяясь какими-то новыми...

Помимо этого, общий характер продуцируемых представлений может зависеть также от конкретного эмоционального настроя, специфической полушарности данного индивида, степени развитости мозговой цитомиелоархитектоники и ряда других немаловажных факторов.

\section{IV}

Формальная логика - это наука, исследующая основные аксиомы и принципы мышления. Иными словами, ее понятийный аппарат являет собой идеализацию множества рабочих структур и контактов, существующих в коре. В то же время смело можно утверждать, что в обыденной человеческой логике нет не только иррационализма или абсурдности, но и вообще ничего такого, что отсутствовало бы в окружающей нас природе. Все силлогистические связи основаны на фундаментальном явлении причинности, ведущем свое начало из незыблемого принципа единообразия и единозакония как во взаимодействиях на микроуровне, так и на высших этапах системной эволюции. С философской точки зрения это незыблемое постоянство естественней всего было б, очевидно, объяснить конечным набором базовых элементарных частиц (включая, разумеется, информоны), обладающих в свою очередь конечным же набором собственных константных характеристик. Причем в случае непринятия концепции глубинной неисчерпаемости материи (в трактовке Анаксагора) подобное обоснование будет даже per definitionem и вполне достаточным. 
Математическая логика более искусственна и абстрактна по сравнению с формальной. Примерно то же самое следует сказать и о кибернетике, которая лишь в начале своего становления хоть как-то соответствовала общему анатомо-физиологическому уровню развития мозговых структур. Если же роботы научатся самостоятельно копировать (ну или, допустим, штамповать) своих электронных «собратьев», то они наверняка уж постараются усовершенствовать заодно любые удобные и выгодные для них пути создания новых вычислительных алгоритмов, превзойдя в этом рано или поздно и собственного творца - человека.

Существует несколько основополагающих принципов и аксиом мышления, все из которых имеют,так или иначе, свои корни в повседневной земной реальности. Вот они.

1. Субъект не может воздействовать на самого себя; откуда уже, кстати, непосредственно вытекает, что ни один субъект никогда не сможет адекватно и полностью познать себя (а особенно, если сравнивать с соседствующими с ним объектами).

2. Критерий истинности - в практике. Данное утверждение больше, пожалуй, мировоззренческого характера, так как основывается на абсолютизации наивно-реалистического восприятия человеком окружающей действительности. Что ipso facto (если, конечно, не привлекать сюда, согласно Оккаму, лишних сущностей) ведет к прерогативе подлинно научных методик над какими бы то ни было религиозно-духовными, включая и весьма модные нынче медитативные «выходы из тела».

3. Всё в жизни нужно рассматривать лишь с точки зрения чего-то конкретного, а не как явление в целом. Это так называемое фундаментальное релятивистское правило, наиболее ярко проявляющееся в отношении атрибутов и предикатов. С ним, однако, не обязаны согласовываться различного рода

высказывания, термины и понятия, связанные с измышлениями человеческого разума и используемые в категориальном аппарате, а также иных абстрактных конструкциях. Причем данное замечание в той же мере касается и следующего пункта.

\section{4. Обо всем можно судить только в вероятностном смысле.} Сюда же вплотную примыкает близкий по духу принцип пространственно-временной неопределенности, у истоков формулировки которого стоял еще Гераклит. Хотя вместе с тем, увы, им нередко злоупотребляют с целью уйти от четкого и конкретного решения того или иного вопроса, что отразилось, $\mathrm{k}$ примеру, на обсуждении проблемы потенциального наличия у электрона свободной воли. Вот почему в серьезных научных 
разработках, пока все другие аргументы не исчерпаны, к принципу неопределенности лучше стараться не апеллировать.

\section{5. Теоретическое познание, в отличие от эмпирического, возможно лишь с обязательным применением силлогистики, индукции, ретроиндукции и глубокого абстрагирования;}

причем всё это - только в рамках тех законов и аксиом, которые детальней уже были рассмотрены выше.

\section{Краткое завершающее резюме}

Вот, пожалуй, и всё, что можно пока на сегодня сказать о запуске и реализации сложнейших мыслительных механизмов на уровне человеческого филогенеза и главенствующей, воистину непереоценимой роли в этом процессе таких, казалось бы, чуждых нашим «кровным» нуклеиновым структурам белковых макроглобулинов. Что же касается всего планетарного человечества, то оно в конце концов полностью осознает свою сущность и предназначение тоже лишь с помощью роботов. Интересно, что как белки, так и высокоорганизованные роботы из не столь уж отдаленного грядущего, способны накапливать и анализировать информацию о себе и внешних объектах, собственно говоря, даже без какой-либо помощи будь то со стороны нуклеотидных цепочек, ну или, соответственно, нынешнего учёного сообщества. То есть здесь, иными словами, еще раз воочию подтверждается предложенная нами ранее гипотеза, суть которой в том, что эволюция космического интеллекта по своим темпам заметно опережает эволюцию живых природных систем. И, таким образом, лишь в человеческом социуме (ибо некая вырванная из него бесхвостая вертикально ходящая особь ничего, увы, сама по себе не значит) для зрелого земного разума - как единственного эффективного орудия на пути постижения истины - уготованы необъятные и весьма к тому же привлекательные перспективы!

*Тут имеется в виду второе издание брошюры 1871 года, поскольку первое (1866 г.) было арестовано и полностью изъято из продажи царской цензурой.

** Впрочем, не исключено, что профессиональные маги и чудотворцы могут даже обращаться за нужной информацией и к аминогруппам, а также глюонам, мезонам (как бы погружаясь при этом в поистине бездонные мнемо-хранилища нижележащих систем).

Эмир Э. Ашшурский (Институт научного прогнозирования, г.Киев, Украина) 
